\title{
Total Protein Profile and Drug Resistance in Candida albicans Isolated from Clinical Samples
}

\author{
Kamal Uddin Zaidi, Abin Mani, Vijay Thawani, and Arti Mehra \\ Biotechnology Pharmacology Laboratory, Centre for Scientific Research \& Development, People’s University, Bhopal 462037, India \\ Correspondence should be addressed to Kamal Uddin Zaidi; zaidi.kamal92@gmail.com
}

Received 17 March 2016; Revised 29 April 2016; Accepted 5 June 2016

Academic Editor: Sharad S. Singhal

Copyright (C) 2016 Kamal Uddin Zaidi et al. This is an open access article distributed under the Creative Commons Attribution License, which permits unrestricted use, distribution, and reproduction in any medium, provided the original work is properly cited.

\begin{abstract}
This study was done to assess the antifungal susceptibility of clinical isolates of Candida albicans and to evaluate its total protein profile based on morphological difference on drug resistance. Hundred and twenty clinical isolates of C. albicans from various clinical specimens were tested for susceptibility against four antifungal agents, namely, fluconazole, itraconazole, amphotericin $\mathrm{B}$, and ketoconazole. A significant increase of drug resistance in clinical isolates of C. albicans was observed. The study showed $50 \%$ fluconazole and itraconazole resistance at $32 \mu \mathrm{g} \mathrm{mL}^{-1}$ with a $\mathrm{MIC}_{50}$ and $\mathrm{MIC}_{90}$ values at 34 and 47 and 36 and $49 \mu \mathrm{g} \mathrm{mL}$, respectively. All isolates were sensitive to amphotericin B and ketoconazole. The SDS-PAGE protein profile showed a prevalent band of $\sim 52.5 \mathrm{kDa}$, indicating overexpression of gene in $72 \%$ strains with fluconazole resistance. Since the opportunistic infections of Candida spp. are increasing along with drug resistance, the total protein profile will help in understanding the evolutionary changes in drug resistance and also to characterize them.
\end{abstract}

\section{Introduction}

Most of the common localised fungal infections are caused by Candida spp. The intensive use of antibiotics made these fungi more drug resistant and a clinical problem. Azoles are considered as the first level of management in Candida infection but there is increase in the resistance [1]. Since C. albicans is the common fungal causative agent in superficial and deep seated candidiasis $[2,3]$ and there has been rise in the incidence of antifungal resistance over the past decade $[4,5]$, it is important to evaluate the development of resistance pattern. Method of typing the organism based on the total protein expressed is useful in characterizing and understanding the development of drug resistance. Analysis of the proteins detects the genetic expression, which is an effective method for characterizing the species based on the morphological changes. The modification of the molecular morphology is a key marker to shift in the drug resistance and thus the protein profile helps in evaluating the antifungal resistance. The SDS-PAGE has been reported for epidemiological typing of Klebsiella spp. [6], aspergillosis [7], and C. albicans [8]. Ying et al. [9] indicated that the fluconazole resistance of
C. albicans has overexpression of ERG11 gene. Keeping these findings in mind, this study was planned to find the incidence of $C$. albicans resistance to antifungal agents and to analyze their antifungal susceptibility pattern and characterize these isolates on the total protein content on their antifungal resistance.

\section{Materials and Methods}

2.1. Specimen. All 120 clinical isolates of C. albicans from catheter tip (CT), urine (U), and high vaginal swab (HVS) were collected from the Department of Microbiology, People's College of Medical Sciences and Research Centre (PCMS and RC), Bhopal, during a month. The culture of $C$. albicans was maintained in the Sabouraud dextrose agar medium. The culture characterizes and microscopic observation was conducted to confirm the strains.

2.2. Antifungal Susceptibility. Well diffusion antifungal susceptibility assay was conducted based on the methodology of Magaldi et al. [10]. Emulsified colonies in the saline solution 
were inoculated in SDA medium in which wells were made using sterilized cork borer. After the moisture got absorbed, the antifungal agents fluconazole $\left(20 \mu \mathrm{g} \cdot \mathrm{mL}^{-1}\right)$, itraconazole (20 $\left.\mathrm{g} \cdot \mathrm{mL}^{-1}\right)$, amphotericin B (100 units), and ketoconazole $\left(20 \mu \mathrm{g} \cdot \mathrm{mL}^{-1}\right)$ were loaded into the well, and it was incubated at $37^{\circ} \mathrm{C}$ for $48 \mathrm{hrs}$.

2.3. Microdilution Assay. The minimal inhibitory concentration (MIC) of the standard drug, fluconazole, itraconazole, ketoconazole, and amphotericin B was determined by microdilution assay by culturing the fungi in Sabouraud dextrose broth and incubating them at $37^{\circ} \mathrm{C}$ for $48 \mathrm{hrs}$. The 96-well microtitre plates were prepared by dispensing $100 \mu \mathrm{L}$ of Sabouraud dextrose broth into each well and $100 \mu \mathrm{L}$ of the antifungal agents in a series from 0.5 to $64 \mu \mathrm{g} \cdot \mathrm{mL}^{-1}$. About $100 \mu \mathrm{L}$ of inoculum was then added to all the wells. The plates were then covered with Parafilm and incubated at $37^{\circ} \mathrm{C}$ for $48 \mathrm{hrs}$. All the procedures were conducted under sterile conditions. The MIC was determined by observing the colour change in the wells after addition of 3-(4,5-dimethylthiazol2-yl)-2,5-diphenyltetrazolium bromide (MTT) which was defined as the lowest concentration that showed no growth.

2.4. Protein Profiling. To evaluate the total protein content the antifungal resistant strains were cultured in media with respective antifungal agents and total protein was extracted and the control was cultivated without antifungal agents. $5 \mathrm{~g}$ of pellet was collected by centrifuging at $5000 \times \mathrm{g}$ for $10 \mathrm{~min}$ and washed twice in normal saline. To these pellets, $100 \mu \mathrm{L}$ of 10x Tris-glycine buffer (Tris $30.3 \mathrm{~g}$, Glycine $144.2 \mathrm{~g}$, SDS $10 \mathrm{~g}$, and distilled water 1 liter: $\mathrm{pH}+8.3$ ) and 10\% SDS were added and sonication was performed in 4 bouts of $30 \mathrm{sec}$ each in ice. After sonication, the supernatant was collected by centrifuging at $5000 \times \mathrm{g}$ for $10 \mathrm{~min}$ at $4^{\circ} \mathrm{C}$ and stored at $-20^{\circ} \mathrm{C}$. The total protein profiling was done by resolving $10 \mu \mathrm{g} \cdot \mu \mathrm{L}^{-1}$ total protein in $10 \%$ sodium dodecyl sulphate polyacrylamide gel electrophoresis [11]. Electrophoresis was performed at a $125 \mathrm{~V}$ for $4 \mathrm{~h}$ in running buffer of $\mathrm{pH}$ 8.3. After electrophoresis, the gels were stained with Coomassie Brilliant Blue R-250. The standards were used to make a plot of $\log$ molecular weight versus mobility of the wide range protein ladder (Himedia).

\section{Results}

C. albicans isolated from 120 infected cases had 51 highrisk patients. The major isolation source was catheterized patients (47.5\%) and others were urine and high vaginal swab. The sources were from the age group 13 to 78 years. It was observed that more women had Candida infection with an infection ratio of $3: 8(\mathrm{M}: \mathrm{W})$ with $71.43 \%$ UTI being higher in women. The isolates showed high sensitivity to amphotericin B and ketoconazole (100\%) whereas $35 \%$ strains had itraconazole resistance and 50\% showed fluconazole resistance. It was observed that the urine isolates had $23.26 \%$ of itraconazole and $13.95 \%$ of fluconazole resistance while the catheter sample showed $38.60 \%$ and $15.79 \%$ resistance, respectively. In men $30.77 \%$ itraconazole resistance
TABLE 1: Antifungal susceptibility patterns of clinical isolates.

\begin{tabular}{lcc}
\hline \multirow{2}{*}{ Antifungal agent } & \multicolumn{2}{c}{ Number of strains isolated from } \\
& HVS, & urine, and catheter tip \\
& Sensitive & Resistant \\
\hline Itraconazole & - & $36(35 \%)$ \\
Fluconazole & - & $41(50 \%)$ \\
Amphotericin B & $120(100 \%)$ & - \\
Ketoconazole & $120(100 \%)$ & - \\
\hline
\end{tabular}

TABLE 2: Minimum inhibitory concentration of clinical isolates.

\begin{tabular}{lccccccccc}
\hline & \multicolumn{8}{c}{ Minimum inhibitory } \\
Antifungal agent & \multicolumn{8}{c}{ concentration $\left(\mu \mathrm{g} \cdot \mathrm{mL}^{-1}\right)$} \\
& 0.5 & 1 & 2 & 4 & 8 & 16 & 32 & 64 \\
& \multicolumn{7}{c}{ Number of inhibited isolates } \\
\hline Fluconazole & 0 & 0 & 0 & 0 & 0 & 0 & 18 & 41 \\
Itraconazole & 0 & 0 & 0 & 0 & 0 & 4 & 13 & 36 \\
Ketoconazole & 13 & 120 & - & - & - & - & - & - \\
Amphotericin B & 22 & 120 & - & - & - & - & - & - \\
\hline
\end{tabular}

and $33.33 \%$ fluconazole resistance were observed, whereas isolates from women had $32.79 \%$ and $36.07 \%$ resistance, respectively, indicating a similar antibiotic resistance in both genders. $64.17 \%$ itraconazole and fluconazole resistance were observed, of which 11 (14.29\%) strains showed resistance to both antifungal agents. The total antifungal susceptibility has been shown in Table 1.

Comparison of MIC pattern (Table 2) of strains showed lowest MIC with amphotericin B and ketoconazole at $0.5 \mu \mathrm{g} \cdot \mathrm{mL}^{-1}$ concentration. Fluconazole sensitivity of $30.51 \%$ was observed at $32 \mu \mathrm{g} \cdot \mathrm{mL}^{-1}$ and itraconazole showed $7.55 \%$ inhibition at $16 \mu \mathrm{g} \cdot \mathrm{mL}^{-1}$. The $\mathrm{MIC}_{50}$ and $\mathrm{MIC}_{90}$ of fluconazole resistance strain were 34 and $47 \mu \mathrm{g} \cdot \mathrm{mL}^{-1}$, respectively, while itraconazole resistance strains showed $\mathrm{MIC}_{50}$ and $\mathrm{MIC}_{90}$ to be 36 and $49 \mu \mathrm{g} \cdot \mathrm{mL}^{-1}$, respectively.

The total proteins were estimated using the method of Lowry et al. [12] which revealed the difference in the protein concentration (Figure 1 ) in a range from 1.05 to $3.22 \mathrm{mg} \cdot \mathrm{mL}^{-1}$. When the organisms were growing in respective antifungal agent, there was decrease in the protein concentration in comparison to those isolates which were not subjected to any antifungal. It was also observed that all the strains which were having both fluconazole and itraconazole resistance were showing high protein concentration $\left(>2 \mathrm{mg} \cdot \mathrm{mL}^{-1}\right)$ than the other resistant strains.

When the strains were further analyzed for its difference in band pattern in SDS-PAGE, the fluconazole and itraconazole resistant strains were having approximately $\sim 62.0 \mathrm{kDa}$ and $\sim 110 \mathrm{kDa}$ similar molecular weight bands; moreover the fluconazole resistant strains were showing $86 \%$ polymorphic protein profiles apart from other strains. It was also observed that $72 \%$ of fluconazole resistant strains had a monomorphic thick band of $\sim 52 \mathrm{kDa}$ (Figure 2). Itraconazole resistant strains had lesser polymorphic similarity of $9.5 \%$ with lesser similarly of profile pattern. The polymorphic band pattern 


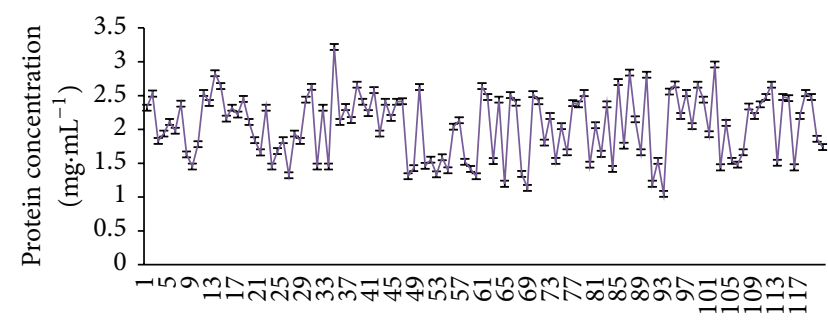

(a)

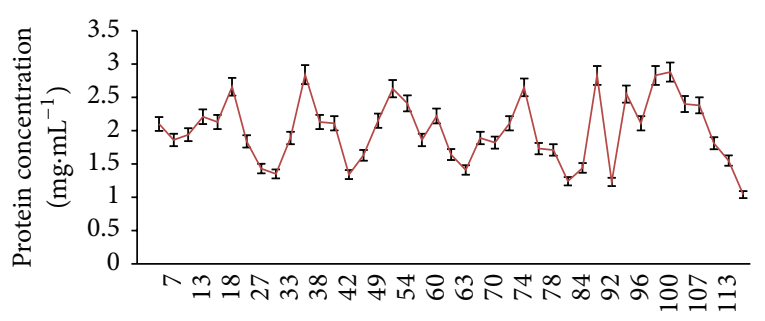

(c)

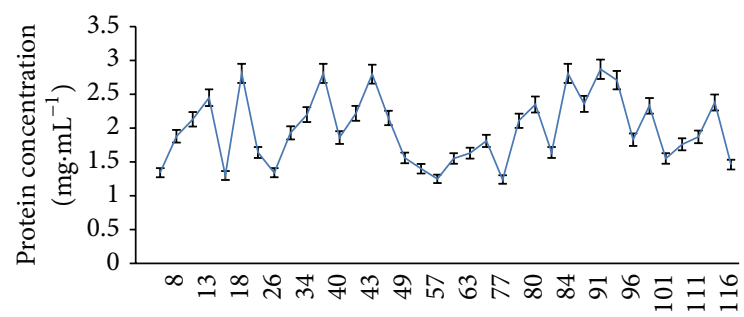

(b)

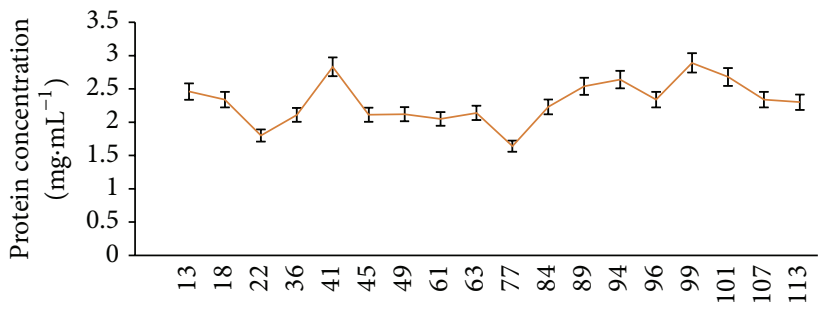

(d)

Figure 1: Protein concentration of drug resistant C. albicans isolated from high vaginal swab, catheter tip, and urine. Control (a), isolates showing itraconazole resistance (b), isolates showing fluconazole resistance (c), and isolates showing itraconazole and fluconazole resistance (d).

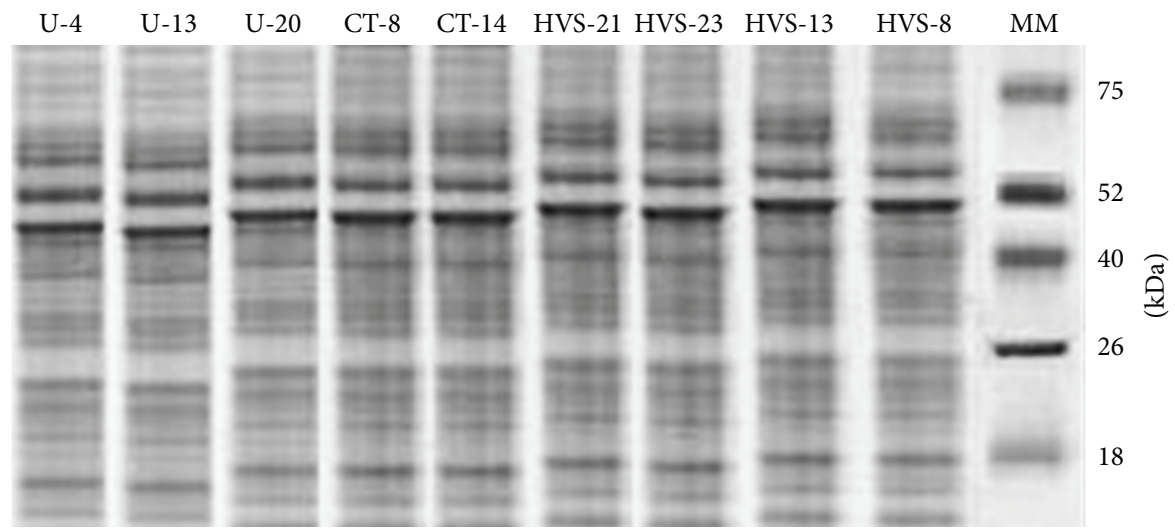

FIGURE 2: Protein profiling of fluconazole resistant Candida albicans isolated from high vaginal swab, catheter tip, and urine. The fluconazole resistant strains had a monomorphic thick band of $\sim 52 \mathrm{kDa}$.

observed is summarized in Table 3. All the strains under study showed $22.73 \%$ of polymorphism. It was observed in all the three dendograms generated for the Candida isolated from high vaginal swab that urine and catheters tip had two clusters (Figure 3). Out of 28 antibiotic resistant high vaginal swab samples 10 strains with fluconazole resistance formed a separated cluster; moreover 7 strains with itraconazole and fluconazole resistance formed a separate cluster along with 11 strains having itraconazole resistance in cluster 2. The 24 antibiotic resistant urine Candida samples formed two clusters in which itraconazole and fluconazole resistance (2 strains) and itraconazole resistance (12 strains) were also clustered together. 36 antibiotic resistant isolates from catheters tip had also shown two clusters where 12 strains of itraconazole resistance formed a cluster and one itraconazole resistance strain showed similarity with the fluconazole resistance (23 strains). It was also observed that itraconazole and fluconazole resistance (2 strains) was clustered with fluconazole resistance strains in the case of catheter isolates. The present study showed similarity in protein profile of resistance strains indicating physiological variation in strains with respect to their antibiotic resistance pattern.

\section{Discussion}

Multidrug resistant candidiasis is an emerging thread, especially affecting women $[13,14]$. It was observed that the catheterized patients were more susceptible to the Candida infections. There was considerable variation in drug resistance of C. albicans isolates from different sites. Decreased susceptibility to the azoles among clinical isolates of $C$. albicans has been earlier reported by [15]. Hadley et al. [16] 
TABLE 3: Banding pattern and molecular weight of clinical isolates.

\begin{tabular}{lccc}
\hline Antifungal agent & Number of isolates & Polymorphic band $(\sim \mathrm{kDa})$ & Number of bands \\
\hline Fluconazole & 41 & $22,34,75.5$ & $23(13.04 \%)$ \\
Itraconazole & 36 & $13.5,24,105.5$ & $18(16.67 \%)$ \\
Fluconazole and itraconazole & 11 & $12,23,54,112$ & $25(16.00 \%)$ \\
Without antifungal agent & 120 & $13,16,31,54,200$ & $22(22.73 \%)$ \\
\hline
\end{tabular}

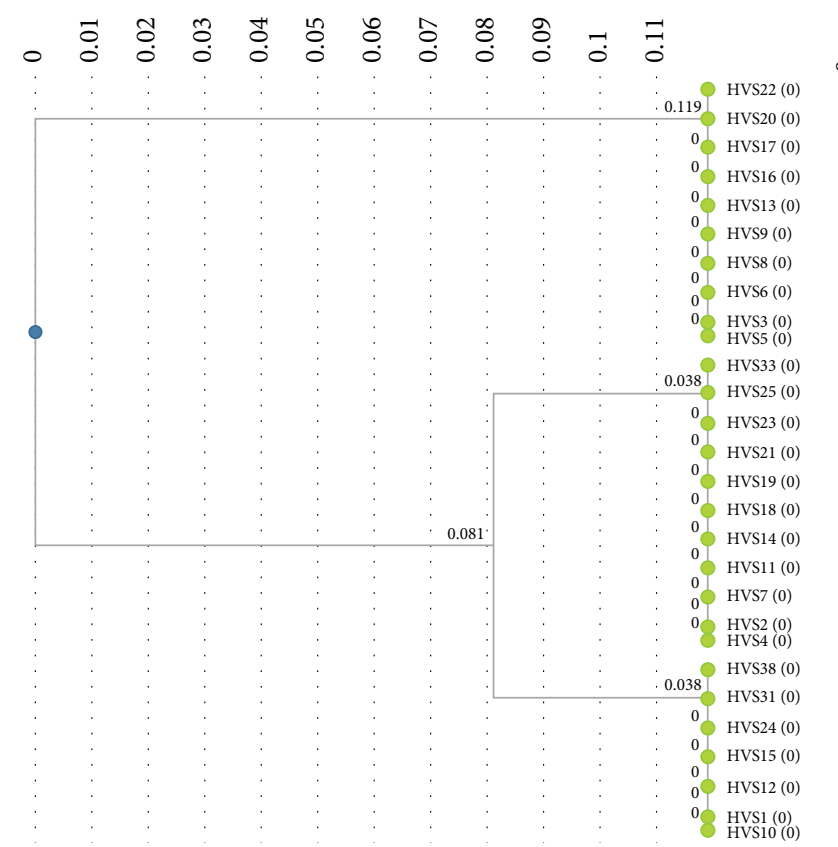

(a)

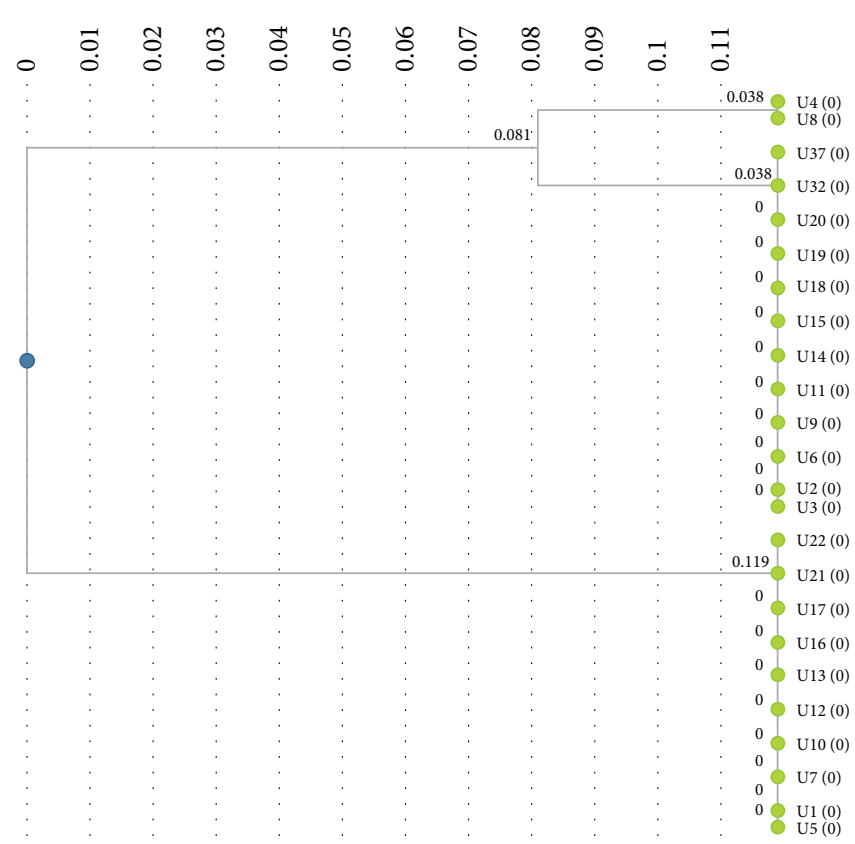

(b)

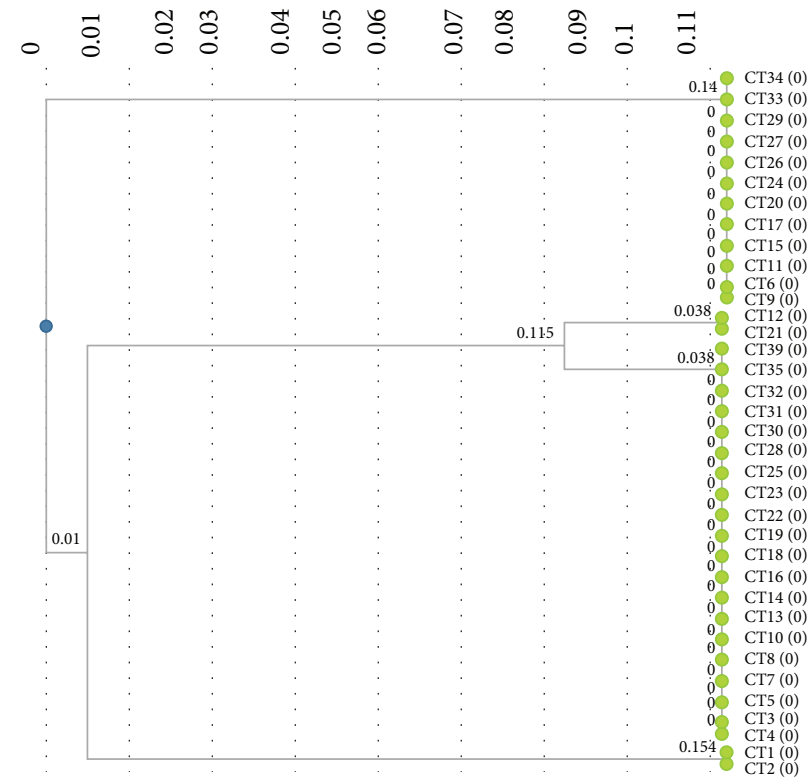

(c)

FIGURE 3: DendroUPGMA: relationship among fluconazole, itraconazole, and fluconazole and itraconazole resistant Candida albicans isolated from high vaginal swab (a), urine (b), and catheters tip (c) based on their protein profiles by SDS-PAGE. 
and Hospenthal et al. [17] suggested that the drug susceptibility determination may contribute to better treatment of microbial infection. It was observed that the C. albicans susceptibility to antifungal agent is at increasing pattern [18].

The increase in the drug resistance is due to the widespread use of broad-spectrum antibiotics and steroids. $C$. albicans is considered as the most pathogenic member of the genus Candida which is the species most commonly isolated from clinical materials, although infections with other species of Candida have been reported $[15,19]$. Mutations seen were associated with antifungal resistance in clinical isolates and these influenced morphogenesis acts as a key trait in the virulence. $C$. albicans diverse capacity to adapt to antifungal exposure [20] might be the reason for the increasing resistance that was observed in the study. Our study adds to the studies done on antifungal susceptibility in clinical strains of C. albicans which carries significance due to its increasing antifungal resistance and clinical importance as a threat of increased infection in immune compromised and hospital acquired infections. The MIC observations were comparable to the study of $[21,22]$ on the correlation of fluconazole MICs in Candida showed good 48 and $24 \mathrm{hr}$ visual MICs in contrast to Espinel-Ingroff et al. [22] who evaluated $48 \mathrm{hr}$ spectrophotometric and visual MICs of fluconazole, itraconazole, voriconazole, and posaconazole for Candida spp. This observation showed that spectrophotometric MICs are more objective than visual MICs. In a study similar to ours, Khosravi et al. [23] demonstrated that the use of SDSPAGE showed a high degree of protein similarity among isolates of C. albicans with low and high virulence. Hence this evaluation can provide promising criteria for evolutionary studies in the increase of the serological changes in the drug resistance.

The SDS-PAGE pattern revealed several characteristic bands common to all isolates having similarity to the findings of Kobayashi and Suginaka [24] where the cell wall protein was used to distinguish serotypes in $C$. albicans. It was observed that the site of the sample had similarity in their total protein profile. The classification of the protein profile in the basis of virulence will help to evaluate the evolutionary difference in the antifungal resistance and constrain the resistance to antifungal in the fungi. The use of SDS-PAGE in epidemiological typing of nosocomial infection in neonates has been reported by Klebsiella spp. [6]. The efficacy of use of SDS-PAGE has also been described in aspergillosis in bronchogenic carcinoma [7]. Rodrigues et al. [8] reported the use of SDS-PAGE for typing of $C$. albicans isolates. They found this method to be important for characterizing the yeast for epidemiological and taxonomic purposes. Based on these findings, we evaluated the use of SDS-PAGE in Candida albicans isolates and performed analysis of the whole cell lysate to characterize the yeast. In the present study the fluconazole and itraconazole resistant strains showed $62 \mathrm{KDa}$ and $110 \mathrm{KDa}$ bands in SDS-PAGE so these strains were discussed. Jackson et al. [25] and Sagatova et al. [26] reported triazole drug resistant C. albicans has fungal lanosterol $14 \alpha-$ demethylase of $62 \mathrm{KDa}$. Song et al. [27] and Ying et al. [9] reported the ERG11 gene in fluconazole resistance of $C$. albicans and is an indicator for fluconazole resistance and has high content of $\sim 50-65 \mathrm{kDa}$ proteins of lanosterol 14 alphademethylase overexpression. The study clearly indicated that there is a difference in the total protein concentration with respective drug resistance, which can be used as a marker of the resistance development. The SDS-PAGE clearly indicated overexpression of the gene in the resistant strain. The protein isolated from the isolates cultivated with antifungal can be used to characterize and estimate the evolutionary scale in developing drug resistance.

\section{Competing Interests}

The authors declare that there are no competing interests regarding the publication of this paper.

\section{Acknowledgments}

The authors are thankful to People's University, People's Group, Bhopal, for laboratory facilities, to carry out this research work.

\section{References}

[1] A. Forastiero, A. C. Mesa-Arango, A. Alastruey-Izquierdo et al., "Candida tropicalis antifungal cross-resistance is related to different azole target (Ergllp) modifications," Antimicrobial Agents and Chemotherapy, vol. 57, no. 10, pp. 4769-4781, 2013.

[2] A. Gullo, "Invasive fungal infections: the challenge continues," Drugs, vol. 69, pp. 65-73, 2009.

[3] A. C. Sajjan, V. V. Mahalakshmi, and D. Hajare, "Prevalence and antifungal susceptibility of Candida species isolated from patients attending tertiary care hospital," Journal of Dental and Medical Sciences, vol. 13, no. 5, pp. 44-49, 2014.

[4] E. Skrodeniene, A. Dambrauskiene, and A. Vitkauskiene, "Susceptibility of yeasts to antifungal agents in Kaunas University of Medicine Hospital," Medicina (Kaunas, Lithuania), vol. 42, no. 4, pp. 294-299, 2006.

[5] G. F. Araj, R. G. Asmar, and A. Z. Avedissian, "Candida profiles and antifungal resistance evolution over a decade in lebanon," Journal of Infection in Developing Countries, vol. 9, no. 9, pp. 997-1003, 2015.

[6] A. Malik, S. E. Hasani, M. Shahid, H. M. Khan, and A. J. Ahmad, "Nosocomial Klebsiella infection in neonates in a tertiary care hospital: protein profile by SDS-page and klebocin typing as epidemiological markers," Indian Journal of Medical Microbiology, vol. 21, no. 2, pp. 82-86, 2003.

[7] A. Malik, M. Shahid, and R. Bhargava, "Prevalence of aspergillosis in bronchogenic carcinoma," Indian Journal of Pathology and Microbiology, vol. 46, no. 3, pp. 507-510, 2003.

[8] C. C. Rodrigues, J. F. Höfling, M. F. Gomes Boriollo et al., "SDS-PAGE and numerical analysis of Candida albicans from human oral cavity and other anatomical sites," Brazilian Journal of Microbiology, vol. 35, no. 1-2, pp. 40-47, 2004.

[9] Y. Ying, Y. Zhao, X. Hu et al., "In vitro fluconazole susceptibility of 1,903 clinical isolates of candida albicans and the identification of ERG11 mutations," Microbial Drug Resistance, vol. 19, no. 4, pp. 266-273, 2013.

[10] S. Magaldi, S. Mata-Essayag, C. H. de Capriles et al., "Well diffusion for antifungal susceptibility testing," International Journal of Infectious Diseases, vol. 8, no. 1, pp. 39-45, 2004. 
[11] U. K. Laemmli, "Cleavage of structural proteins during the assembly of the head of bacteriophage T4," Nature, vol. 227, no. 5259, pp. 680-685, 1970.

[12] O. H. Lowry, N. J. Rosebrough, A. L. Farr, and R. J. Randall, "Protein measurement with the Folin phenol reagent," The Journal of Biological Chemistry, vol. 193, no. 1, pp. 265-275, 1951.

[13] B. Mathema, E. Cross, E. Dun et al., "Prevalence of vaginal colonization by drug-resistant Candida species in collegeage women with previous exposure to over-the-counter azole antifungals," Clinical Infectious Diseases, vol. 33, no. 5, pp. E23E27, 2001.

[14] F. De Bernardis, S. Arancia, S. Sandini, S. Graziani, and S. Norelli, "Studies of immune responses in Candida vaginitis," Pathogens, vol. 4, no. 4, pp. 697-707, 2015.

[15] M. E. Fadda, G. S. Podda, M. B. Pisano, M. Deplano, and S. Cosentino, "Prevalence of Candida species in different hospital wards and their susceptibility to antifungal agents: results of a three year survey," Journal of Preventive Medicine and Hygiene, vol. 49, no. 2, pp. 69-74, 2008.

[16] S. Hadley, J. A. Martinez, L. McDermott, B. Rapino, and D. R. Snydman, "Real-time antifungal susceptibility screening aids management of invasive yeasts infections in immunocompromised patients," Journal of Antimicrobial Chemotherapy, vol. 49, no. 2, pp. 415-419, 2002.

[17] D. R. Hospenthal, C. K. Murray, and M. G. Rinaldi, “The role of antifungal susceptibility testing in the therapy of candidiasis," Diagnostic Microbiology and Infectious Disease, vol. 48, no. 3, pp. 153-160, 2004.

[18] E. M. Mokaddas, N. A. Al-Sweih, and Z. U. Khan, "Species distribution and antifungal susceptibility of Candida bloodstream isolates in Kuwait: a 10-year study," Journal of Medical Microbiology, vol. 56, no. 2, pp. 255-259, 2007.

[19] M. A. Pfaller, "Nosocomial candidiasis: emerging species, reservoirs, and modes of transmission," Clinical Infectious Diseases, vol. 22, no. 2, pp. S89-S94, 1996.

[20] R. H. Jensen, K. M. T. Astvad, L. V. Silva et al., "Stepwise emergence of azole, echinocandin and amphotericin B multidrug resistance in vivo in Candida albicans orchestrated by multiple genetic alterations," Journal of Antimicrobial Chemotherapy, vol. 70, no. 9, pp. 2551-2555, 2015.

[21] L. Ostrosky-Zeichner, J. H. Rex, P. G. Pappas et al., "Antifungal susceptibility survey of 2,000 bloodstream Candida isolates in the United States," Antimicrobial Agents and Chemotherapy, vol. 47, no. 10, pp. 3149-3154, 2003.

[22] A. Espinel-Ingroff, F. Barchiesi, M. Cuenca-Estrella et al., "Comparison of visual 24-hour and spectrophotometric 48-hour MICs to CLSI reference microdilution MICs of fluconazole, itraconazole, posaconazole, and voriconazole for Candida spp.: a collaborative study," Journal of Clinical Microbiology, vol. 43, no. 9, pp. 4535-4540, 2005.

[23] A. R. Khosravi, M. Riazipour, H. Shokri, M. L. Mousavi, and M. Mahmoudi, "Characterization of the similarity of protein patterns and virulence of clinical Candida albicans isolates," Journal of Biological Sciences, vol. 8, no. 4, pp. 760-766, 2008.

[24] K. Kobayashi and H. Suginaka, "Comparison of cell wall and membrane proteins from eight Candida species," Sabouraudia, vol. 22, no. 4, pp. 341-344, 1984.

[25] C. J. Jackson, D. C. Lamb, T. H. Marczylo et al., "A novel sterol $14 \alpha$-demethylase/ferredoxin fusion protein (MCCYP51FX) from Methylococcus capsulatus represents a new class of the cytochrome P450 superfamily," Journal of Biological Chemistry, vol. 277, no. 49, pp. 46959-46965, 2002.
[26] A. A. Sagatova, M. V. Keniya, R. K. Wilson, B. C. Monk, and J. D. A. Tyndall, "Structural insights into binding of the antifungal drug fluconazole to Saccharomyces cerevisiae lanosterol $14 \alpha$ demethylase," Antimicrobial Agents and Chemotherapy, vol. 59, no. 8, pp. 4982-4989, 2015.

[27] J. L. Song, J. B. Harry, R. T. Eastman, B. G. Oliver, and T. C. White, "The Candida albicans lanosterol 14- $\alpha$-demethylase (ERG11) gene promoter is maximally induced after prolonged growth with antifungal drugs," Antimicrobial Agents and Chemotherapy, vol. 48, no. 4, pp. 1136-1144, 2004. 

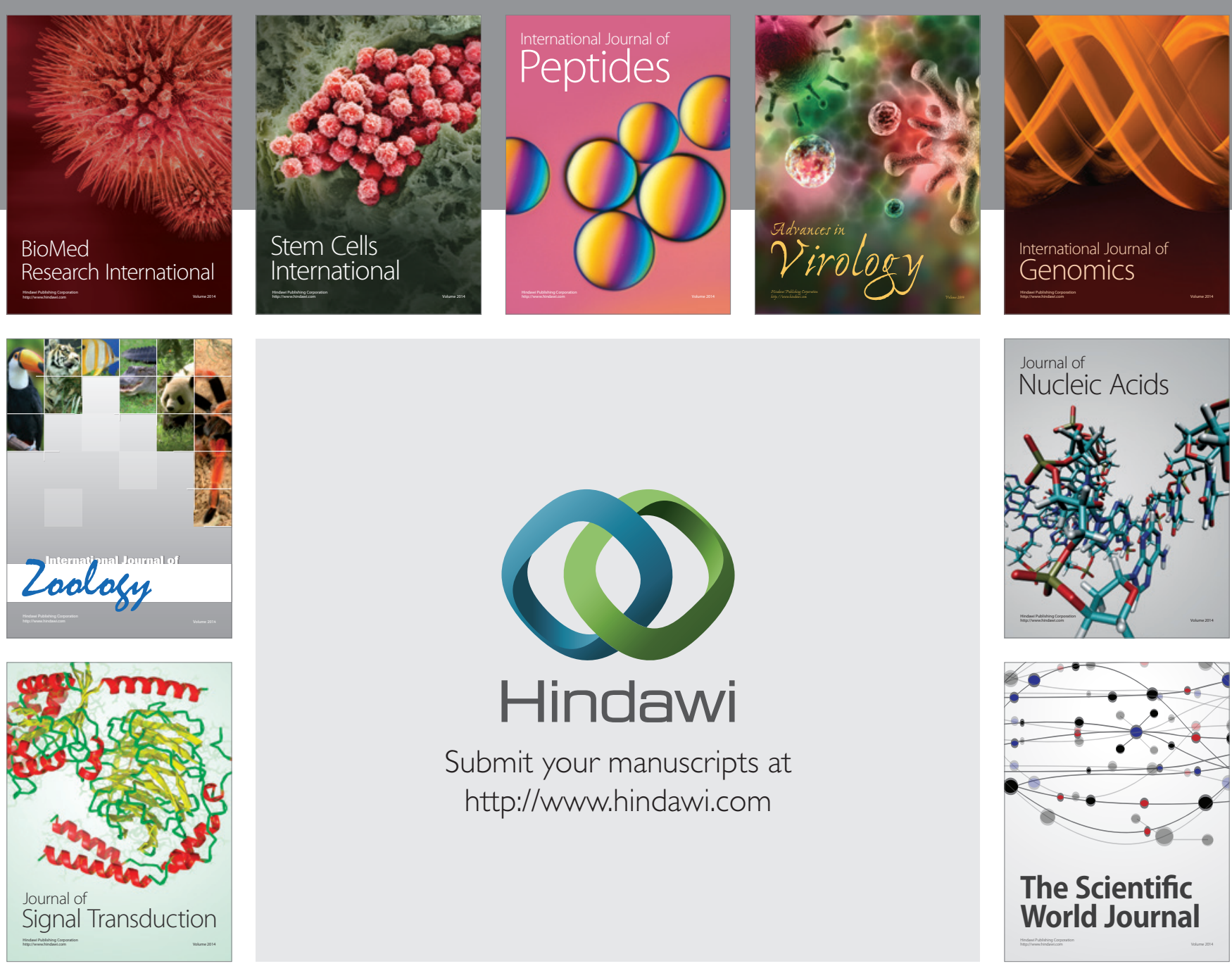

Submit your manuscripts at

http://www.hindawi.com
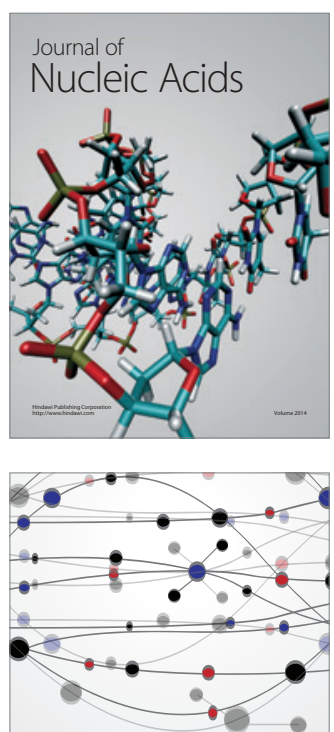

The Scientific World Journal
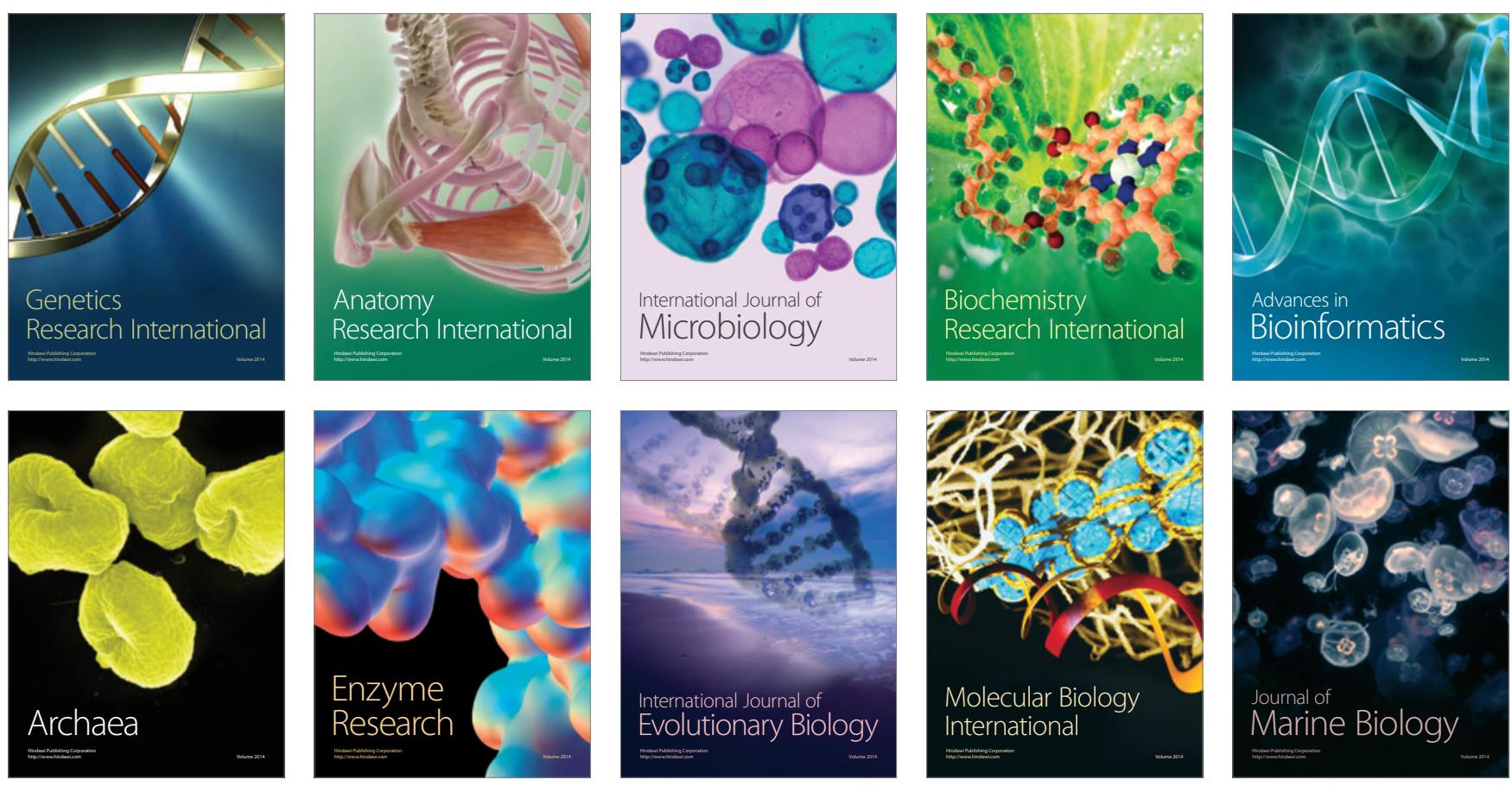